\title{
ĐÁNH GIÁ KẾT QUẢ PHẪU THUÂTT THAY KHỚP HÁNG BÁN PHẦN KHÔNG CEMENTE ĐIỀU TRI GÃY LIÊN MẤU CHUYỂN XƯƠ'NG ĐÙI NGƯỜI CAO TUỔI TẠI BỆNH VIỆN VIÊTT ĐỨC NĂM 2017-2020
}

\section{TÓM TẮT}

Gãy vùng nền cổ- mấu chuyển xương đùi là loại gãy thường gặp, đặc biệt là người cao tuổi. Mục tiêu nghiên cứu: Đánh giá kết quả phẫu thuật thay khớp háng bán phần không cemente điều trị gãy xương vùng nền cổ - mấu chuyển xương đùi người cao tuổi . Nghiên cứu mô tả cắt ngang 147 bệnh nhân có độ tuổi trung bình là 80.5 tuổi, tỷ lệ nữ/nam là $2 / 1$, tại Bệnh viện Việt Đức từ 01/2017 tới tháng 06/2020. Kểt quả phẫu thuật tốt và rất tốt đạt $80,9 \%$, khá đạt 14,3 $\%$, trung bình và xấu 4,8\%. Phẫu thuật thay khớp háng bán điều trị gãy LMC là một giải pháp tốt cho các bệnh nhân cao tuổi.

Tứ khóa: Gãy liên mấu chuyển xương đùi, thay khớp háng bán phần

\section{SUMMARY}

THE RESULT OF PARTIAL HIP REPLACEMENT FOR INTERTROCHANTERIC FRACTURE IN

ELDER PATIENTS- VIETDUC HOSPITAL

The intertrochanteric fracture is quite common, especially in elder patients. Objective: Evaluate the result of partial hip replacement non cemente for intertrochanteric fracture in elder patients with 147 intertrochanteric fracture patients in VietDuc hospital from January 2017 to June 2020, average age is 80.5 years old, female/male ratio is $2 / 1$. The results of surgery is: $80,9 \%$ good, $14,3 \%$ moderate and $4,8 \%$ is bad. Hemi-hip replacement for transtrochanteric fracture is the good surfical treatment for old osteoporosis patient.

Keywords: intertrochanteric fracture, Partial hip replacement

\section{I. ĐĂT VẤN ĐỀ}

Gãy LMC khá phổ biến, chiếm $55 \%$ các loại gãy đâuu trên xương đùi, 95\% gặp ở người cao tuổi, phụ nữ gặp nhiêu gấp 2-3 lần nam giới.

Gãy LMC có tần xuất tăng theo tuổi thọ; người cao tuổi sức khỏe yếu và bị loãng xương nên chỉ một lực tác động nhỏ, như ngã đập mông xuống nền cứng có thể gãy xương.

Điều trị gãy $L M C$ có thể bằng phương pháp bảo tồn hoặc điều trị phẫu thuật. Trước kia, điều

\footnotetext{
*BV Việt Đức

**BV Nhiệt đới trung ương

Chịu trách nhiệm chính: Vũ Văn Khoa

Email: drvuvankhoa@gmail.com

Ngày nhận bài: 24.2.2021

Ngày phản biên khoa học: 29.3.2021

Ngày duyệt bài: 6.4 .2021
}

Vũ Văn Khoa*, Nguyễn Ngọc Hân**

trị bảo tồn được sử dụng nhiều với phương pháp bất động bằng bó bột, nẹp hoặc xuyên kim kéo liên tục, nhưng thời gian điều trị lâu, bệnh nhân gặp nhiều biến chứng và tỷ lệ tử vong cao do các bệnh toàn thân. Ngày nay, với tiến bộ cuả trang thiết bị, kỹ thuật ngoại khoa và gây mê hồi sức, nên chỉ định điều trị phẫu thuật ngày càng mở rộng, làm giảm thời gian điều trị, tử vong và nâng cao chất lượng sống người bệnh.

Điều trị phẫu thuật có thể bằng kết hợp xương (KHX) hoăc thay khớp háng. Phẫu thuật KHX sử dụng nhiều với nhiều phương pháp khác nhau như: Găm kim, bắt vít, đóng đinh ender, đinh gama... mục đích là bất động xương vững, phục hồi tốt về giải phẫu giúp xương liền, tập phục hồi chức năng sớm, tránh các biến chứng toàn thân và người bệnh sớm trở lại cuộc sống lao động và sinh hoat bình thường. Tuy nhiên, ở người cao tuổi, do loãng xương nên KHX thường bất động không vững, thường phải bất động thêm bằng bột và thời gian bất động dài nên không thể PHCN sớm, hậu quả bệnh nhân phải nằm lâu, gặp nhiều biến chứng toàn thân như loét do tỳ đè, viêm phổi, nhiễm trùng tiết niệu, tăng các biến chứng của các bệnh mạn tính như tim mạch, đái tháo đường đã có từ trước, kể cả tử vong, đây là mặt tồn tồn tại của phương pháp này.

Để khắc phục nhược điểm của các phương pháp trên đối với người cao tuổi, phẫu thuật thay khớp háng bán phần (Bipolar) được lựa chọn. Nghiên cứu này nhằm mục tiêu: "Đánh giá kêt quả phẫu thuật thay khớp háng bán phần trong điều trị gãy LMC ơ người cao tuôii".

\section{II. ĐỐI TƯỢNG VÀ PHƯƠNG PHÁP NGHIÊN CỨU}

Nghiên cứu mô tả cắt ngang 147 bệnh nhân cao tuổi gãy LMC tại Bệnh viện Việt Đức từ tháng 01/2017 tới tháng 06/2020

Tiêu chuân lựa chon bệnh nhân:

+ Bệnh nhân cao tuổi $\geq 70$, gãy LMC

+ Tiền sử đi lai bình thường, không có bệnh toàn thân đang diễn biến nặng kèm theo

+ Đầy đủ hồ sơ bệnh án

+ Theo dõi tối thiểu 06 tháng

\section{Quy trinh kỹ thuât}

+ Đánh giá trước phẫu thuât: Đánh giá toàn trạng hô hấp, tuần hoàn, các bệnh phối hợp, $X Q$ kiểm tra mức độ gãy, loãng xương. Chuẩn bị mố 
và điều trị các bệnh phối hợp.

+ Quy trình phẫu thuật:

- Vô cảm bằng gây tê tủy sống hoặc gây mê.

- Đặt tư thế bệnh nhân nằm nghiêng, đánh rửa vùng mổ.

- Rach da và bộc lộ ổ gãy.

- Bộc lộ ổ gãy xương và chỏm xương đùi.

- Lấy bỏ chỏm xương đùi, giữ lại các mảnh xương vùng mấu chuyển.

- Đo đường kính chỏm.

- Ráp ống tủy, đặt chuôi khớp háng nhân tạo không cement.

+ Đặt chuôi dài với các Bệnh nhân loãng xương (T-score $\leq-2.5$ ) hoăc ổ gãy không vững (các gãy mà đường gãy dưới mấu chuyển bé).

+ Đặt chuôi ngắn với các gãy vùng khối mấu chuyển vững, chưa loãng xương (T-score $\geq-2.5$ ).

- Tạo hình lại khối mấu chuyển xương đùi với các mảnh xương rời, cố định mảnh gãy bằng chỉ thép,

- Lắp chỏm khớp có kích thước phù hợp với ổ cối.

- Nắn khớp vào ổ cối và kiểm tra độ vững, biên độ vận động khớp.

- Cầm máu, bơm rửa, khâu bao khớp, dẫn lưu, đóng vết mổ.

+ Theo dõi sau mổ: Điều trị kháng sinh, giảm đau, chống đông, điều trị các bệnh nội khoa khác kèm theo, thay băng vết mồ, theo dõi dẫn lưu, chụp XQ khung chậu sau mổ và tập phục hồi chức năng từ ngày thứ 2 sau mổ.

\section{Đánh giá kết quả điều trị}

Đánh giá chức năng khớp háng theo chỉ số của Merle d'Aubigné - Postel [1] : Mức độ đau, biên độ vận động khớp và khả năng đi bộ ( tính theo độ vững) với các mức độ:

17-18 điểm: Rất tốt

15-16 điểm: Tốt

13-14 điểm: Khá

10-12 điểm: Trung bình

$<10$ điểm : Xấu

Đánh giá XQ khớp háng (ngay sau mổ, sau mổ 1,3,6,12,18 tháng): Tư thế khớp sau mồ, trật khớp, lỏng chuôi, mòn ổ cối, tiêu xương... (tối thiểu 6 tháng)

- Xử lý số liệu bằng phần mềm SPSS 16.0

- Đạo đức nghiên cứu: Nghiên cứu được hội đồng bệnh viện phê duyệt, các bệnh nhân đồng thuận tham.

\section{KẾT QUẢ NGHIÊN CỨU}

Trong nghiên cứu, có 93 BN nữ $(63,3 \%)$ và 54 nam (36,7\%). Độ tuổi trung bình là 80,5 tuổi, thấp nhất là 70 tuổi, cao nhất là 99 tuổi, độ tuối gặp nhiêu nhất là $75-89$ chiếm $85,8 \%$. BN chủ yểu gãy do TNSH chiếm 92,6\%. Tất cả BN liền vết mổ tốt. Thời gian nằm viện 10-28 ngày, trung bình 12,8 ngày.

Các biến chứng trong và sớm sau phẫu thuật (trong thời gian nằm viện)

Bảng 1: Biến chứng sớm sau mồ

\begin{tabular}{|c|c|c|}
\hline Biến chứng & $\mathbf{N}$ & $\mathbf{\%}$ \\
\hline Không & 135 & 91,7 \\
\hline Tắc mạch phổi & 1 & 0,7 \\
\hline Tắc tĩnh mạch sâu chi dưới & 2 & 1,4 \\
\hline Trật khớp & 3 & 2,1 \\
\hline Viềm phối & 5 & 3,4 \\
\hline Tim mạch & 1 & 0,7 \\
\hline Tống số & $\mathbf{1 4 7}$ & $\mathbf{1 0 0}$ \\
\hline
\end{tabular}

Nhận xét: Có $12 \mathrm{BN}$ biến chứng sớm trong thời gian nằm viện, chiếm $8,1 \%$. Trong đó, có 1 bệnh nhân tắc mạch phổi, 5 bệnh nhân viêm phổi, là biến chứng nặng sau mổ

Biến chứng xa sau mổ (sau khi ra viện, theo dõi tối thiểu 6 tháng)

\begin{tabular}{|c|c|c|}
\hline Biến chứng & $\mathbf{N}$ & $\mathbf{\%}$ \\
\hline Lóng chuôi & 3 & 2,1 \\
\hline $\begin{array}{c}\text { Viêm phối, nhiềm trùng tiết } \\
\text { niệu, tắc tĩnh mạch sâu chi dưới }\end{array}$ & 7 & 4,7 \\
\hline Gãy xương đùi & 1 & 0,7 \\
\hline Không & 136 & 92,5 \\
\hline Tống số & $\mathbf{1 4 7}$ & $\mathbf{1 0 0}$ \\
\hline
\end{tabular}

Nhận xét: có 3 bệnh nhân lỏng chuôi khớp háng sau mổ, 7 bệnh nhân có các biến chứng của nằm lâu, 1 bệnh nhân gãy xương đùi dưới chuôi do ngã.

Kết quả chung sau mổ

Bảng 3.2. Đánh giá kêt quả chung ( $n=147)$

\begin{tabular}{|c|c|c|c|c|c|c|}
\hline $\begin{array}{c}\text { Kết } \\
\text { quả }\end{array}$ & $\begin{array}{c}\text { Rất } \\
\text { tốt }\end{array}$ & Tốt & Khá & $\begin{array}{c}\text { Trung } \\
\text { bình }\end{array}$ & Xấu & Tổng \\
\hline $\begin{array}{c}\text { Số } \\
\text { lượng }\end{array}$ & 74 & 45 & 21 & 5 & 2 & 147 \\
\hline Tỷ lệ \% & 50,3 & 30,6 & 14,3 & 3,4 & 1,4 & 100,0 \\
\hline
\end{tabular}

Nhận xét: Kết quả chức năng khớp háng đạt tốt và rất tốt là $80,9 \%$, khá là $14,3 \%$, trung bình $3,4 \%$ và xấu $1,4 \%$.

\section{BÀN LUÂ̂N}

Trong nghiên cứu của chúng tôi độ tuổi trung bình là 80.5 tuổi, thấp nhất là 70 tuổi, cao nhất là 99 tuổi, đây là nhóm bệnh nhân lớn tuổi đều bị loãng xương nhiều nên chỉ cần ngã đập mông nhẹ xuống nền cứng là gãy xương. Tỳ lệ nữl nam $\approx 2 / 1$. Tỷ lệ này phù hợp với các tác giả khác $[2,3,4]$

Thời gian bệnh nhân nằm viện trung bình 13,7 ngày, trong đó có $89.8 \%$ nằm viện khoảng 15 ngày, bệnh nhân nằm viện lâu hơnn nhóm bệnh khác là do tình trạng sức khỏe yếu, mắc nhiều bệnh toàn thân như các bệnh tim mạch, hô hấp... nên phải điều trị nội khoa trước, trong 
và sau mổ. Đăc biêt có bênh nhân trên 20 ngày do phải điều trị toàn thân trước mổ và sau mổ: điều trị cao huyết áp, suy hô hấp... Thời gian nằm viện của $\mathrm{BN}$ như các tác giả $[3,4]$

Trong nghiên cứu 100\% BN không sảy ra biến chứng trong mổ và liền vết mổ tốt; Kết quả này do sự phối hợp của các bác sĩ chuyên ngành hồi sức và kháng sinh tốt nên hạn chế được tai biến. Có 3 trường hợp (2\%) trật khớp háng sau mổ, các bệnh nhân này được gây mê, nắn lại khớp, không phải mổ lại. Có 5 BN biến chứng viêm phổi, $1 \mathrm{BN}$ suy tim trên nền mắc bệnh ĐTÐ và các bệnh lý hô hấp và tim mạch tuổi già, trong đó có 1 bệnh nhân diễn biến nặng xin về, các bệnh nhân khác được điều trị ổn định.

Trong 147 BN có 1 bệnh nhân biến chứng tắc mach phổi, $1 \mathrm{BN}$ tắc tĩnh mach đùi, được phát hiện kịp thời, điều trị ổn định theo phác đồ của khoa hồi sức tim mạch, ra viện ổn định và ra viện.

Theo dõi xa thẩy có 3 bệnh nhân lỏng chuôi khớp háng, tuy nhiên bệnh nhân vẫn đi lại trên khung được, điều trị giảm đau bệnh nhẩn hết đau, do tuổi cao nên gia đình khổng muốn mổ lại. Có 1 bệnh nhân sau mổ 9 tháng bị ngã, gãy xương đùi dưới chuôi, phải mổ nep vít, buộc chỉ thép để cố định xương, bệnh nhân này sau đó liên xương, vận động tốt. Đặc biệt, có 7 bệnh nhân có các biến chứng khác như viêm phổi, nhiễm trùng tiết niệu, khi ra viện ổn đinh, đi lại vận động tốt về nhà bệnh nhân vận động kém, không phục hồi chức năng nên có các biến chứng do nằm lâu; trong đó có 2 bệnh nhân tử vong trong 7 và 15 tháng sau mổ, tuy nhiên các bệnh nhân này đều có bệnh nền và vận động kém; các bệnh nhân khác ổn định.

Kết quả chung của nhóm nghiên cứu 80,9\% BN đạt kết quả tốt và rất tốt, $14,3 \%$ đạt khá, $3,4 \%$ đạt kết quả trung bình và $1,4 \%$ kết quá xấu. Kết quả này phù hợp với kết quả nghiên cứu của các tác giả $[2,3,4,5,6]$ cho thây sự phù hợp của phương pháp với đối tượng người già bi loãng xương nặng gãy LMC. Từ đó đưa ra chỉ định thay khớp háng bán phần căn cứ vào các yều tố: người cao tuổi, loãng xương, mắc các bênh toàn thân, cơ sở chuyên khoa, điều kiện gây mê, hồi sức trước, trong và sau mổ phải đảm bảo tốt.

\section{KẾT LUÂN}

Nghiên cứu trên 147 BN gãy LMC người cao tuổi được điêu trị bằng phẫu thuật thay khớp háng bán phần không cemente tại bệnh viện Việt Đức thời gian từ 01/2017-06/2020, thu được kết quả:

- Có 12 BN (8,1\%) gặp biến chứng sớm sau mổ: Tắc mạch phổi, tắc tĩnh mạch chi dưới, trật khớp, viêm phổi và biến chứng tim mạch

2/147 BN (1,3\%) tử vong sau 7 và 15 tháng đầu do các bệnh lý toàn thân: suy hô hấp, trụy tim mach, TBMMN...

- Kết quả thay khớp: $80,9 \%$ tốt và rất tốt, 14,3\% khá, trung bình 3,4\%, xấu 1,4\%

- Phẫu thuật thay khớp háng bán phần, điều trị gãy LMC là một giải pháp tốt cho người già loãng xương.

\section{MộT SỐ HìNH ẢNH TRƯớC VÀ SAU MỔ THAY KHỚP HÁNG BÁN PHẦN, BỆNH NHÂN GÃY LIÊN MẤU CHUYỂN XƯƠNG ĐÙI}
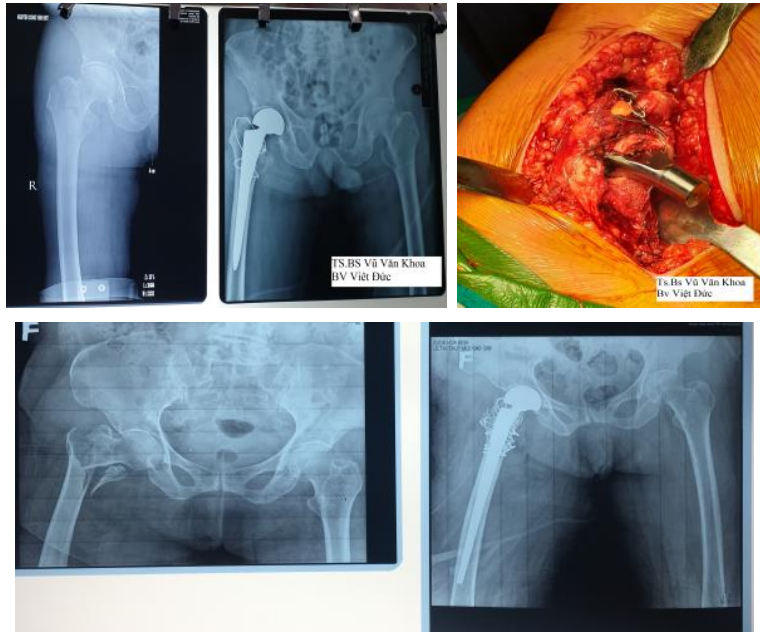

TÀI LIỆU THAM KHẢO

1. Merle d'Aubigné R. (1970), "Cotation chiffrée de la fonction de la hanche". Rev Chir Ortho Reparatrice Appar Mot, 56 (5), pp 481-86.

2. Nguyê̂nn Manh Khánh, Đoàn Việt Quân, Nguyển Xuẩn Thùy "Thay khớp háng bán phân ở bệnh nhân gãy liên mấu chuyển không vững" Tap chí chấn thương chỉnh hình việt nam số 1 2012, tr 39-44.

3. Phí Mạnh Công (2009). "Đánh giá kết quả điều tri gãy liên mấu chuyển xương đùi ở người trên 70 tuối bằng kết hợp xương nẹp vít động tại bệnh viện Xanh pôn và bệnh viện 198". Luận văn thạc sĩ $y$ hoc, tr 40-41.

4. Hoàng Thế Hùng (2013). "Đánh giá kết quả điều tri gãy liên mâu chuyển xương đùi ở người cao tuổi bằng thay khớp háng bán phân bipolar". Luận văn thac sỹ y học, học viện quân $y$, tr 50-51.

5. Sancheti K. H., Sancheti P. K., Shyam A. K., Patil S., Dhariwal Q., Joshi R., (2010), "Primary hemiarthroplasty for unstable osteoporotic intertrochanteric fracture in the elderly, a retrospective case series", Indian journal orthropaedic, 44, 428-434.

6. Hong-Man Cho, MD, Seung-Ryul Lee, MD... "Standard Type Cemented Hemiarthroplasty with Double Loop and Tension Band Wiring for Unstable Intertrochanteric Fractures in the Elderly" ] Korean 
Hip Soc 22(2): 159-165, 2010

7. Choy, Won Sik; Ahn, Jae Hoon; Ko, JoonHyuk; Kam, Byoung Sup; Lee, Do-Hyun. Cementless Bipolar Hemiarthroplasty for Unstable Intertrochanteric Fractures in Elderly Patients. Clinics in Orthopedic Surgery, Volume 2 (4).
PubMed Central - Dec 1, 2010

8. Harwin SF, Stern RE, Kulick RG. Primary Bateman-Leinbach bipolar prothetic replacement of the hip in the treatment of unstable Intertrochanteric Fractures in Elderly. Orthopedics 1990;13: 1131-1136.

\section{HIỆU QUẢ LỌC MÁU Ở BỆNH NHÂN BÊ̂NH THẬN MẠN GIAI ĐOẠN CUỐI CHAYY THÂ̂N NHÂN TAO CHU KỲ̛ TẠI BỆNH VIỆN HỮU NGH! ĐA KHOA NGHỆ AN}

\section{TÓM TẮT}

Bệnh thận mạn đặc biệt là bệnh thận mạn giai đoạn cuối là vấn đề sức khỏe toàn câuu với tỷ lệ mắc bệnh cao. Thận nhân tạo chu kỳ là phương pháp điều trị thay thế thận được sử dụng phổ biến nhất hiện nay. Mục tiêu nghiền cứu: Đánh giá hiệu quả lọc máu ở bệnh nhân bênh thận mạn giai đoạn cuối chạy thận nhân tạo chu kỳ. Phương pháp nghiên cứu: Nghiên cứu can thiêp so sánh trước sau. Kết quả: (1) Chỉ số URR trung bình là $64,13 \pm 3,25$; chỉ số Kt/V trung bình là $1,22 \pm 0,12$; (2) Có $67,57 \%$ tổng số bệnh nhân đạt chỉ số URR và $75,68 \%$ tổng số bệnh nhân đat chỉ số Kt/V; (3) Các triệu chứng lâm sàng giảm đáng kể sau lọc máu so với trước lọc máu nhất là các triệu chứng mệt mỏi, buồn nôn và đau đâu. Kết luận: Phần lớn bệnh nhân bệnh thận mạn đạt chỉ số URR và Kt/V sau lọc máu.

Tư khóa: Thận nhân tạo, bệnh thận mạn

\section{SUMMARY}

\section{THE EFFECTIVENESS OF DIALYSIS IN PATIENTS WITH END-STAGE RENAL DISEASE ON HEMODIALYSIS IN NGHE AN GENERAL HOSPITAL}

Chronic kidney disease, especially end-stage renal disease (ESRD), is a global health problem with a high incidence. Artificial kidney is the most commonly used kidney replacement therapy. Objectives of the study: To evaluate the effectiveness of dialysis in patients with ESRD on hemodialysis. Research methodology: Intervention research. Results: (1) The average URR is 64,13 $\pm 3,25$; The average Kt / V is $1,22 \pm 0,12 ;$ (2) $67,57 \%$ of patients had appropriate URR and $75,68 \%$ of patients had appropriate Kt/V; (3) Clinical symptoms significantly reduced after dialysis compared to before dialysis, especially symptoms of fatigue, nausea and headache.

${ }^{1}$ Trường Đại học Y khoa Vinh

${ }^{2}$ Bệnh viện Hữu nghị đa khoa Nghệ An

Chịu trách nhiệm chính: Nguyễn Văn Tuấn

Email: tuanminh1975@gmail.com

Ngày nhận bài: 18.2.2021

Ngày phản biên khoa học: 26.3.2021

Ngày duyệt bài: 5.4.2021
Nguyễn Văn Tuấn', Nguyễn Thị Thùy Linh²

Conclusion: Most patients with CKD achieved URR and $\mathrm{Kt} / \mathrm{V}$ after dialysis.

Keywords: Artificial kidney, chronic kidney disease

\section{I. ĐẶT VẤN ĐỀ}

Bênh thân man tính là vấn đề sức khỏe có tính toàn cầu với tỷ lệ mắc bệnh tăng nhanh và chi phí điều trị cao. Các phương pháp điều trị thay thế thận suy đã cải thiện đáng kể tỉ lệ sống sót của bệnh nhân bệnh thận mạn giai đoạn cuối, tuy nhiên tỉ lệ tử vong của nhóm bệnh nhân này còn cao dù đã có nhiều tiến bộ lớn trong điều trị [5].

Trên thế giới có khoảng 1,5 triệu người mắc bệnh thận mạn giai đoạn cuối đang được điêuu trị thay thể thận. Tại Trung Quốc năm 2012 tỷ lệ mắc bệnh thận mạn là $10,8 \%$ tương đương 119,5 triệu người. Điều tra của Nguyễn Văn Tuấn năm 2015 tại Nghệ An cho thây tỉ lệ bệnh thận mạn tại Nghệ An là 1,04\% [2].

ở nước ta việc điều trị bệnh thận mạn giai đoạn cuối bằng phương pháp ghép thận còn hạn chể do đó loc máu bằng chay thận nhân tạo chu kỳ là phương pháp điều trị được lựa chọn phổ biến nhất. Tại Nghệ An số lượng các cơ sở chạy thận nhân tạo tăng nhanh trong thời gian gần đây để đáp ứng nhu cầu loc máu cho người bệnh. Xuất phát từ thực tế đó chúng tôi nghiên cứu đề tài này nhằm mục tiêu: "Đánh giá hiệu quả loc máu ở bênh nhân bệnh thận mạn giai đoạn cuối chạy thận nhân tạo chu kỳ tại Bệnh viện hữu nghị đa khoa tỉnh Nghệ An".

\section{II. ĐỐI TƯợNG VÀ PHƯƠNG PHÁP NGHIÊN CỨU}

1. Đối tượng nghiên cứu. Bệnh nhân bệnh thận mạn giai đoạn cuối chạy thận nhân tạo chu kỳ tại Khoa nội thận - thận nhân tạo, Bệnh viện hữu nghị đa khoa Nghệ An.

- Tiêu chuẩn lứa chọn:

+ Bệnh nhân bệnh thận mạn giai đoạn cuối chạy thận nhân tạo chu kỳ 3 lần/1 tuần, 1 lần 